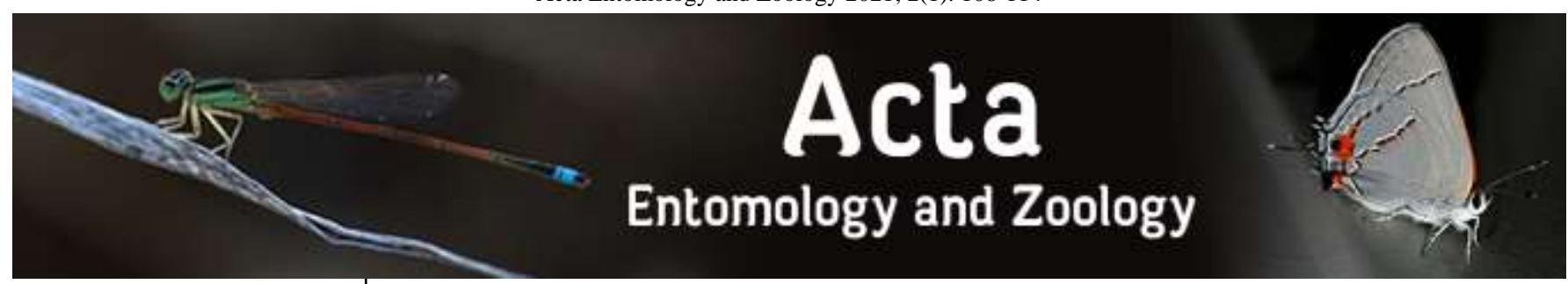

E-ISSN: 2708-0021

P-ISSN: 2708-0013

www.actajournal.com

AEZ 2021; 2(1): 108-114

Received: 21-12-2020

Accepted: 27-12-2021

\section{Akata Rani}

Ms Student, Department of

Entomology, Faculty of

Agriculture Hajee Mohammad

Danesh Science and

Technology University,

Dinajpur-5200, Bangladesh

Md. Abdul Ahad

Professor, Faculty of agriculture, Department of

Entomology, Faculty of

Agriculture Hajee Mohammad

Danesh Science and

Technology University,

Dinajpur-5200, Bangladesh

MA Hossain

Professor, Faculty of agriculture, Department of

Entomology, Faculty of

Agriculture Hajee Mohammad

Danesh Science and

Technology University,

Dinajpur-5200, Bangladesh
Corresponding Author:

Akata Rani

Ms Student, Department of

Entomology, Faculty of

Agriculture Hajee Mohammad

Danesh Science and

Technology University,

Dinajpur-5200, Bangladesh

\section{Life history traits and food consumption of hog plum leaf beetle Podontia 14-punctata (Chrysomelidae: Coleoptera)}

\author{
Akata Rani, Md. Abdul Ahad and MA Hossain
}

DOI: $\underline{\text { https://doi.org/10.33545/27080013.2021.v2.i1b.35 }}$

\begin{abstract}
The objective of this article is to find out the life history traits and food consumption of Hog Plum Leaf Beetle Podontia 14-punctata or Podontia quatodecimpunctata (Chrysomelidae: Coleoptera). However, the result of life history traits Podontia 14-punctata reveals that the pre-oviposition, oviposition and incubation period of the hog plum leaf beetle were agverage $19.8 \pm 0.55,8.0 \pm 0.21$ and $5.7 \pm 0.15$ days, respectively. The average number of eggs laid in a cluster by the female was 41.5 and hatching rate was $96.27 \%$. The eggs were, more or less, oval round and at the end freshly laid eggs become yellow in colour, naked and are arranged in multiple layers usually two, before hatching it became dull yellowish-white. Dark black head and legs of grub were visible through egg membrane just before hatching. The mean duration of the $1^{\text {st }}, 2^{\text {nd }} 3^{\text {rd }}, 4^{\text {th }}$ instars larvae and were $3.3 \pm 0.15,3.4 \pm 0.16,3.3 \pm 0.15$ and 3.7 \pm 0.15 days. But the mean duration of the pupa varied from 14-17 days days. The total developmental periods from egg to adult were 37.1 days. In addition, a larva consumed leaf of hog plum $32.127 \mathrm{~cm}^{2}$ or $3.8234 \mathrm{~g}$ during its total developmental period. But the final instars larvae consumed the highest amount of leaf.
\end{abstract}

Keywords: Life history, food consumption, podontia 14-punctata, chrysomelidae

\section{Introduction}

The hog plum (Spondias mangifera L.) is a popular subtropical fruit, locally known as "Amra". It grows in Bangladesh but good quality "Amra" is cultivated commercially in Barishal district and the fruit is consumed mostly in green stage and is also used as pickle, chattni, murbba etc. (Ahmed 1969). It is grown throughout the tropics (Maniruzzaman 1988; Verheij and Coronel 199; Ahmed 1969). The fourteen spotted leaf beetle, Podontia 14punctata or Podontia quatodecimpunctata (Chrysomelidae: Coleoptera) is distributed through South East Asia (Husain and Ahmed 1977; Howlader 1993) ${ }^{[8]}$. It is the most destructive pest of hog plum not only Bangladesh but also in India (Lefroy 1971) ${ }^{[10]}$. It is grown throughout the tropics (Maniruzzaman 1988; Verheij and Coronel 1991). It is reported to be used as fodder in different parts of India like Asham, Madhya prodesh, Punjab and Uttar Pradesh (Singh 1982) ${ }^{[15]}$. It is a voracious leaf eating insect of feeds on the hog plum (Spondias mangifera L.) both the young and aged plant. The young plant is completely defoliated and at severe infestation the plant is die out. The fourteen spotted leaf beetle, Podontia quatodecimpunctata belongs to the family Chrysomelidae under the order of Coleoptera is distributed throughout South East Asia and feeds on S. mangifera Wild of the hog plum tree. The hog plum leaf beetle is a serious pest of the hog plum. Both adults and larvae are voracious leaf feeder. As a result, of their attack, the tree becomes completely defoliated. It is reported that in Bangladesh, the beetles appear in April, abundant during July to September and disappear in October. The peak period of defoliation is August and September (Beeson 1941; Baksha 1997) ${ }^{[5,3]}$. The damage due to the pest is severe during the period when the tree is in full foliage (Mondol 1975) ${ }^{[11]}$. The insect causes damage about $96 \%$ of the levees of hog plum. Average infestation of the leaves is $50 \%$, the beetles completely defoliate the tree and cause stunting of the growth of the three eventually reduces fruit size and yield. During off season the insect pupate in the soil in hibernating condition. All four larval stages retain a fecal coat, possibly mimicking bird dropping (Barlow 1900; Stebbing 1914; Baksha 1997) ${ }^{[4,16,3]}$. The study of biology or life history traits provides the information about the integrated management of insect, amount of insecticide, 
types of insecticide and spray method a pest (Rono et al 2008) ${ }^{[2]}$. There are many works on the life history traits and food consumption on many insect pest such as biology or life history traits and food consumption of lemon butterfly Papilio demoleus L. (Papilionidae: Lepidoptera) (Karim et al. 2008) ${ }^{[9]}$, life history traits and food consumption of mango defoliator, Cricula trifenestrata Helfer (Amin et al. 2008) [2, 9], biology of lady beetle Micraspis discolor (Fab.) (Coccinellidae: Coleoptera). (Chowdhury et al.2008) ${ }^{[16]}$ etc. But from the review of literatures, it was found that there very limited information about biology and food consumption of hog plum leaf beetle, $P$. quatodecimpunctata. For this reason, the objective of this article is to find out the life history traits and food consumption of hog plum leaf beetle Podontia 14-punctata (Chrysomelidae: Coleoptera), which is very much necessary for the management of this pest.

\section{Materials and Methods}

The study on life history traits and leaf consumption morphology of hog plum leaf beetle, Podontia quatodecimpunctata were done in the laboratory of Entomology of Hajee Mohammad Danesh Science \& Technology University, Dinajpur, Bangladesh from May, 2017 to August, 2017. The mean monthly temperature was $30 \pm 2{ }^{\circ} \mathrm{C}$ and relative humidity $80 \pm 5 \%$.

\section{Collection and Rearing of adult beetle}

Adult hog plum leaf beetles were collected from the hogplum orchard and placed in pair (one male and one female) in several petridishes $(150 \mathrm{~cm} \times 90 \mathrm{~cm})$. Fresh hog-plum leaves were supplied daily in each petri dish to ensure availability of food. After egg laying the beetles were transferred to another Petridis. The date of egg laying and hatching period were recorded.

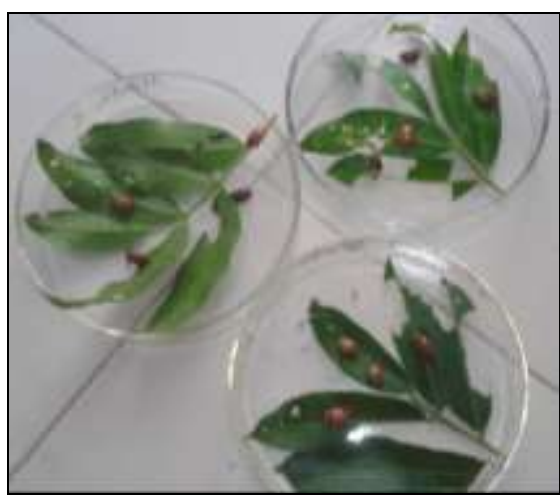

Fig 1: Rearing of Adult beetle

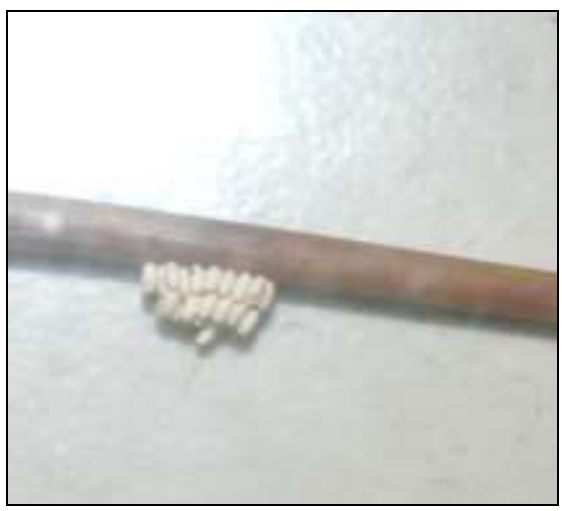

Fig 2: Egg mass

\section{Rearing of larvae}

The young larvae immediately were isolated carefully after hatching and placed in separate petridishes with the help of soft brush. One larva was placed in one petri dish and ten replications were used for the same. Fresh food was provided twice daily when needed. Data were taken carefully to record the time of moulting, number of instar and duration of each larval instar. Observation was made daily four times at 6:00 hour's intervals. At the end of final instar, when feeding was stopped the larvae were kept undisturbed and some soil were provided in the glass jar to help for the making their pupal chamber until the emergence of adults.

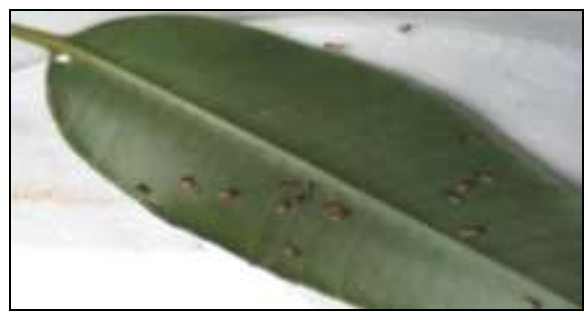

Fig 3: First instar larva

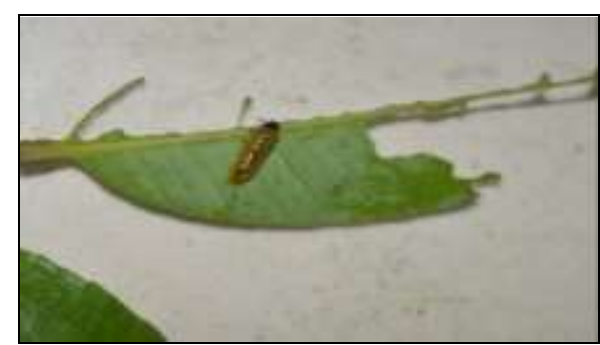

Fig 4: Second instar larva

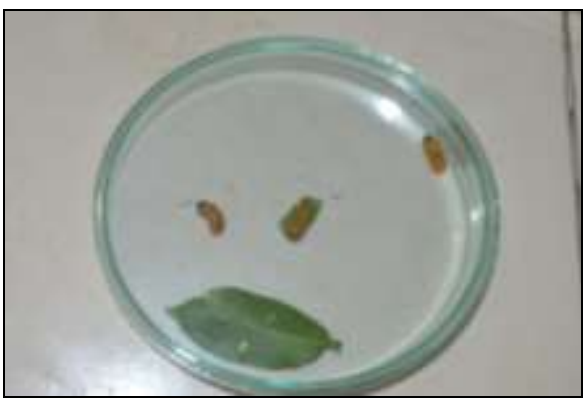

Fig 5: Third instar larva

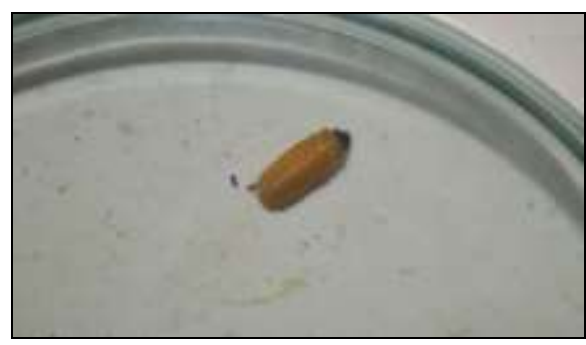

Fig 6: Fourth instar larva

\section{The pre-pupal and pupal periods}

The pre-pupal and pupal periods of the male and female were also recorded. For observation of pre-ovipositional, ovipositional period, fecundity and longevity of the adults, the newly emerged adults were confined in a pair of each sex in a petridish for allowing them to mate and lay eggs with adequate supply of fresh hog-plum leaves daily. 


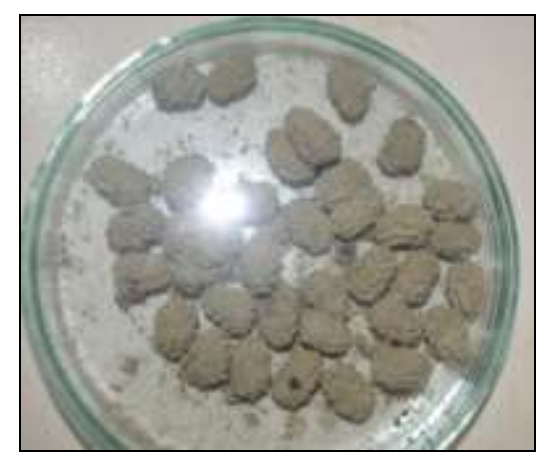

Fig 7: Pupa with earthen cell

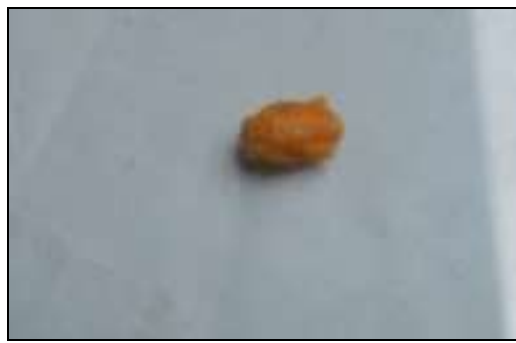

Fig 8: Pupa of hog plum leaf beetle

\section{Leaf consumption by the larvae and adult beetle}

After hatching the 1st instar larva was placed in a petridish and adequate fresh foods were supplied after molting the 2nd, 3rd and 4th instar larvae were reared in same manner. Fresh foods were also supplied to new adults. The foliage consumed by larva and adult were recorded daily in terms of area and weight basis by subtracting leaf area and weight before and after consumption by placing leaves in an electronic automatic area meter (Model L-13,000, LI-COR, Nebraska, USA) and Mettlers Digital Balance (Model-MR 220. No. 971373).

The medium mature leaves were supplied by making small pieces with the help of a sharp scissor. The initial weight of supplied leaf pieces in each petridish was taken separately with the help of electric balance. To find out the weight of consumed leaves (g) in 24 hours (A), the weight of unused leaves (C) and the weight of moisture loss from the control petridish (D) were subtracted from the initial weight of supplied leaves (B).

Calculation can be as follows: $\mathrm{A}=\mathrm{B}-(\mathrm{C}+\mathrm{D})$,
Where,

$\mathrm{A}=$ Weight of consumed leaves $(\mathrm{g})$

$\mathrm{B}=$ Initial weight of supplied leaves $(\mathrm{g})$

$\mathrm{C}=$ Weight of unused leaves $(\mathrm{g})$

$\mathrm{D}=$ Weight of moisture loss from the control petridish $(\mathrm{g})$

The process was repeated in case of all larval instars. Leaf consumption by each larval instar in different days was recorded.

\section{Results and Discussions}

The Results, discussions about the life history traits or biology and leaf consumption of hog plum leaf beetle Podontia 14-punctata are harmonically presented in different figures and tables and are presented below:

\section{Mating of hog plum leaf beetle}

Mating of $P$. quatodecimpunctata took place 17 to 23 days after adult emergence. Copulation generally commenced from early morning and continued for 6-7 hours. The insect mated more than once in its life.

Hossain et al. (2004) ${ }^{[7]}$ reported that mating of this insect took place 10-17 days after adult emergence and mating duration was $5.89 \pm 1.4$ hours. According to Sardar and Mondal (1983) ${ }^{[13]}$ mating took place 2-3 weeks after emergence.

\section{Pre-oviposition, oviposition and incubation period of hog plum leaf beetle}

The pre-oviposition period varied from 17 to 23 days with an average of $19.8 \pm 0.55$ days (Figure 1). Mondal (1975) ${ }^{[11]}$ reported that pre-oviposition period was 20.2 days with a maximum of 23 days of the beetle in April to August. Branson and Johnson (1973) stated that the pre-oviposition period varied from 14 days under laboratory condition of these insects, which were very close to the present findings. The oviposition period ranged from 7 to 9 days. The mean oviposition period was $8.0 \pm 0.21$ days (Figure 1). Hossain et al. (2004) ${ }^{[7]}$ found that the mean ovipositional period of this beetle was $8.8 \pm 0.4$ days and parallel of the present study. The incubation period varied from 5 to 6 days with an average of 5.7 \pm 0.15 days (Fig. 1). Singh and Misra (1989) ${ }^{[14]}$ found that the incubation period of same insect was 7-8 days. Baksha (1997) ${ }^{[3]}$ also reported that the incubation period of this beetle was 7-8 days. Sardar and Mondal (1983) ${ }^{[13]}$ observed that the eggs of this beetle hatched in 56 days.

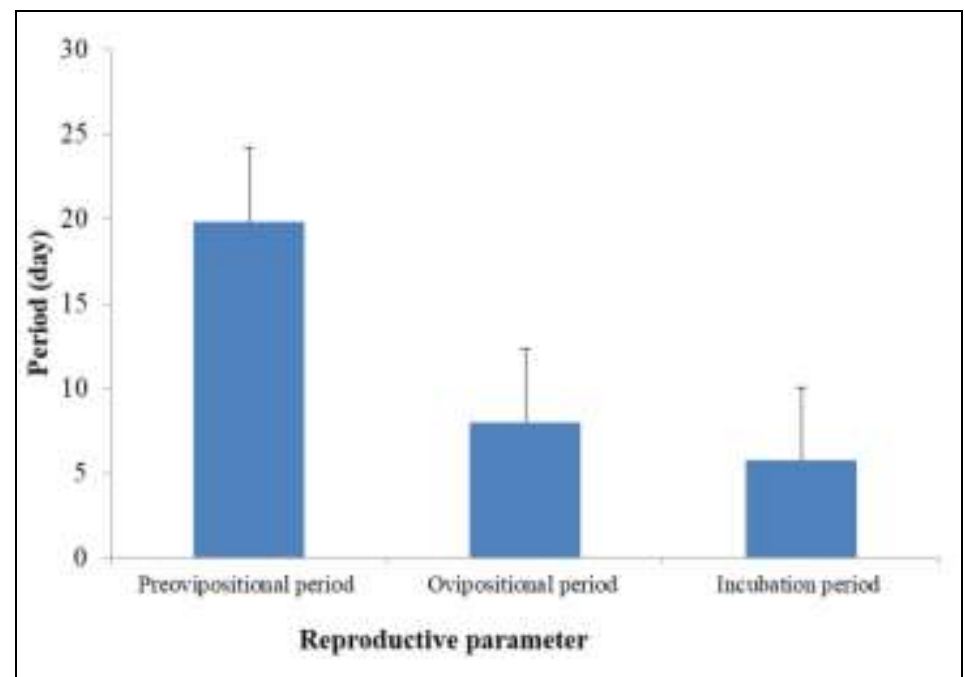

Fig 1: Pre-oviposition, oviposition and incubation periods (mean \pm SE) of $P$. quatodecimpunctata 


\section{Eggs of hog plum leaf beetle}

The female laid eggs on the leafstalk and under the lower surface of leaves and occasionally at the bottom and side wall of the petridishes. The egg was laid in clusters of 33 to 50. The egg remains attached vertically to the leaf surface or on the wall of the rearing petridishes with sticky secretions. The eggs were, more or less, oval round and at the end freshly laid eggs become yellow in colour, naked and are arranged in multiple layers usually two, before hatching it became dull yellowish-white. Dark black head and legs of grub were visible through egg membrane just before hatching.

\section{Larval duration of hog plum leaf beetle}

The larva was soft bodied, elongated, somewhat flattened and consisted for 4 larval instars. The total larval period varied from 12.0 to 16.0 days an average of $13.7 \pm 0.11$ days (Figure 2).

First instars of hog plum leaf beetle: The duration of the 1st instars larvae varied from 3 to 4 days within an average of 3.3 \pm 0.15 day (Figure 2). Hossain et al. (2004) ${ }^{[7]}$ found that the mean duration of first instars larva of $P$. quatodecimpunctata was $3.75 \pm 0.13$ days.

\section{Second instars of hog plum leaf beetle}

The result of the duration of the 2 nd instars revealed that the duration varied from 3 to 4 days and the mean duration was $3.4 \pm 0.16$ days (Figure 2). Hossain et al. (2004) ${ }^{[7]}$ found that the mean duration of 2nd instars larvae of $P$. quatodecimpunctata was 3.6 days.

\section{Third instars of hog plum leaf beetle}

The duration of 3rd instars larva varied from 3 to 4 days with an average of $3.3 \pm 0.15$ days (Fig. 2). Hossain et al. (2004) ${ }^{[7]}$ also reported that the duration of 3rd instars larva of $P$. quatodecimpunctata was 3.3 days which in similar to the present study.

\section{4th instars of hog plum leaf beetle}

Observation made on the duration of the 4th instars larva with an average of $3.7 \pm 0.15$ days (Fig. 2). with minimum of 3 days and maximum 4 days. Hossain et al. (2004) ${ }^{[7]}$ also reported that the duration of 3rd instars larva of $P$. quatodecimpunctata was 4.0 days which is similar to the present study.

Sardar and Mondal (1983) ${ }^{[13]}$ reported he average total larval period from first to final instar was 16.6 days and the mean duration of each instar was the same (4 days), which support the duration of the of $1^{\text {st }} 2^{\text {th }} 3^{\text {th }}, 4^{\text {th }}$ instars larval period and total larval period.

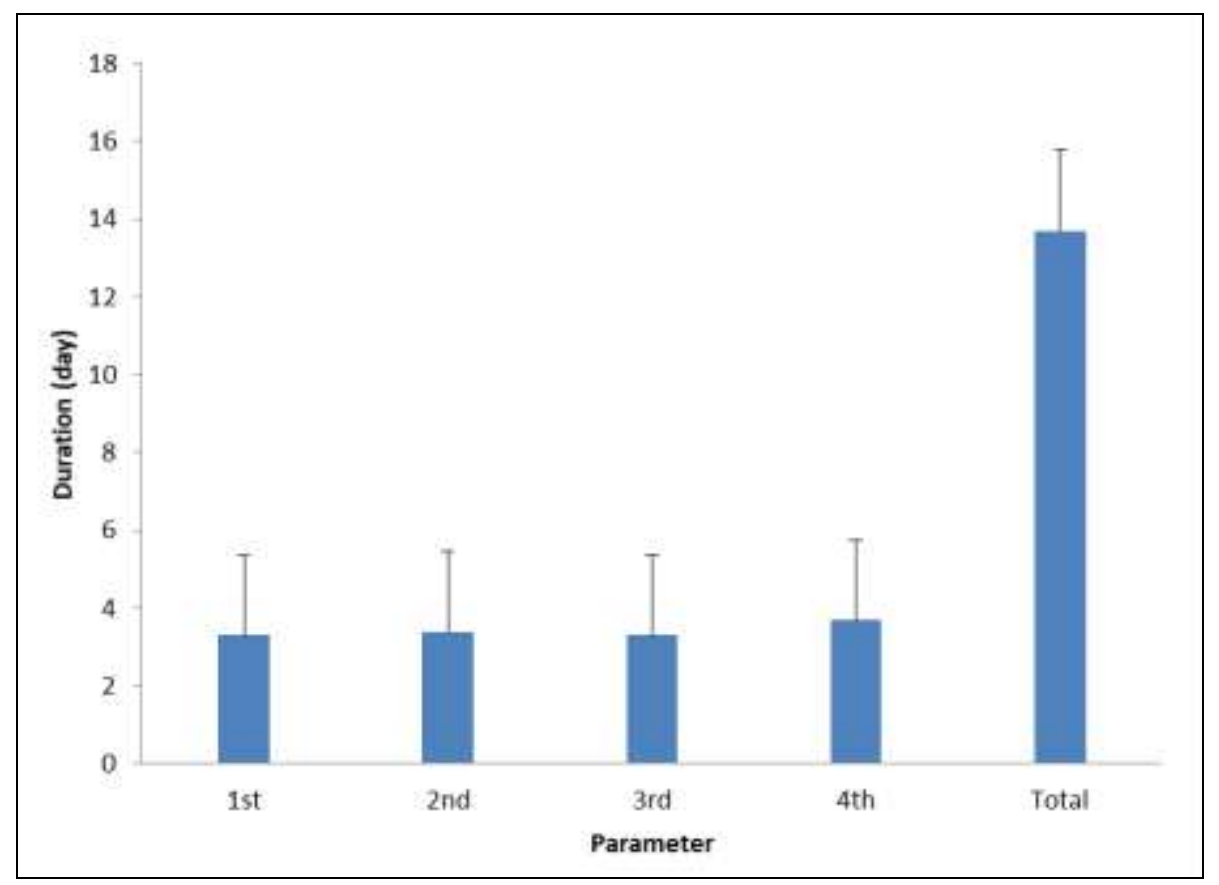

Fig 2: Duration of different larval instars (mean $\pm \mathrm{SE})$ of $P$. quatodecimpunctata

\section{Pre-pupal and pupal duration of hog plum leaf beetle}

Before pupation, the full grown larvae entered a short prepupal stage, lasting 2-3 days (Figure 3). At the beginning of this stage of the larvae stopped feeding, entered into the soil and selected a site for pupation. It made on oval earthen chamber within which it pupated. Sardar and Mondal (1983) ${ }^{[13]}$ reported that the duration of prepupal stage of this beetle varied from 2-3 days which is similar to present observation.
The pupal cell was found in the soil at a depth of 1 to $2 \mathrm{~cm}$. The mean duration of the pupa varied from 14-17 days (Figure 3). Sardar and Mondal (1983) ${ }^{[13]}$ observed that the pupal period of hog plum beetle for female was about 30days. Singh and Misra (1989) ${ }^{[14]}$ also observed that the duration of this beetle was 14-29 days. Baksha (1997) [3] reported that the pupal stage of this beetle was lasted for 1530 days. From the above discussion it may be concluded that there is considerable variation of pupal periods in this present work and it might be due to temperature variation. 


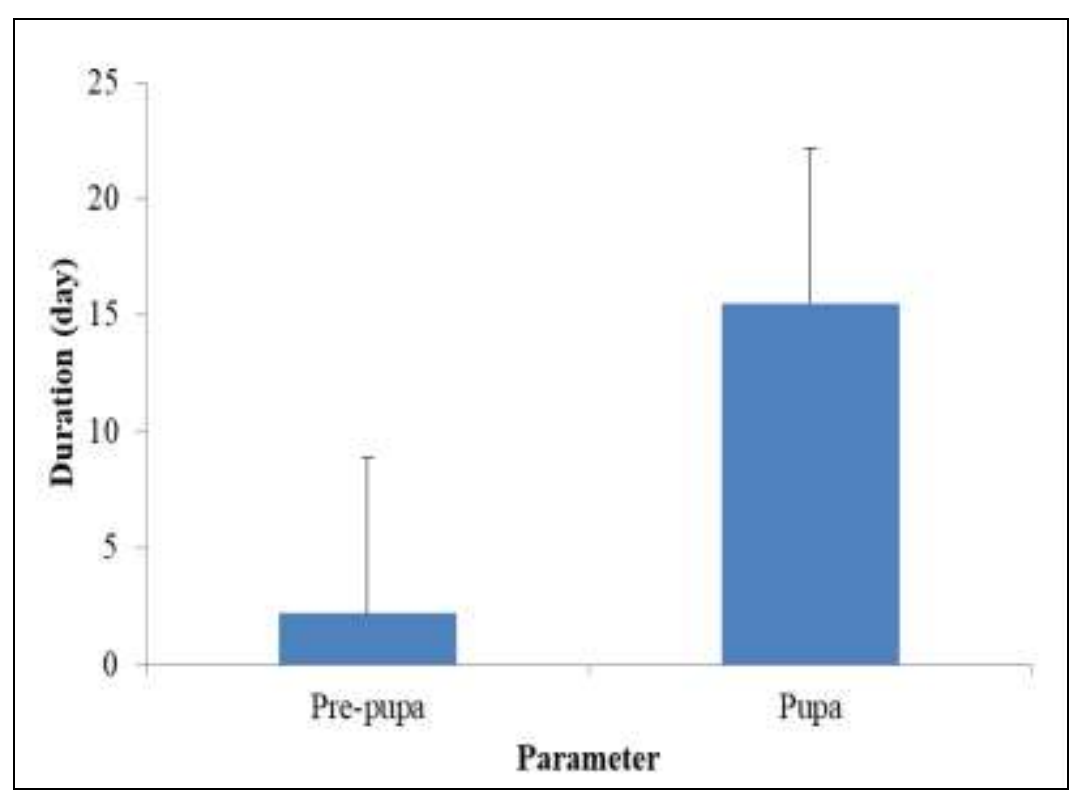

Fig 3: Pre-pupal and pupal periods (mean \pm SE) of $P$. quatodecimpunctata

\section{Adult longevity}

The longevity of adult beetles was counted from the emergence of the adult to its death. In general the longevity of the male beetle was shorter than the female. The longevity of male beetles varied from 18 to 23 days with an average of $20.6 \pm 0.52$ days (Figure 4). But the longevity of the female beetles varied from 35 to 43 days with an average of 39.9 \pm 2.23 days (Figure 4). Sardar and Mondal (1983) ${ }^{[13]}$ described the longevity of this adult beetle as 4452 days which is slightly differed with the present study. It may be the effect of food and environmental conditions.

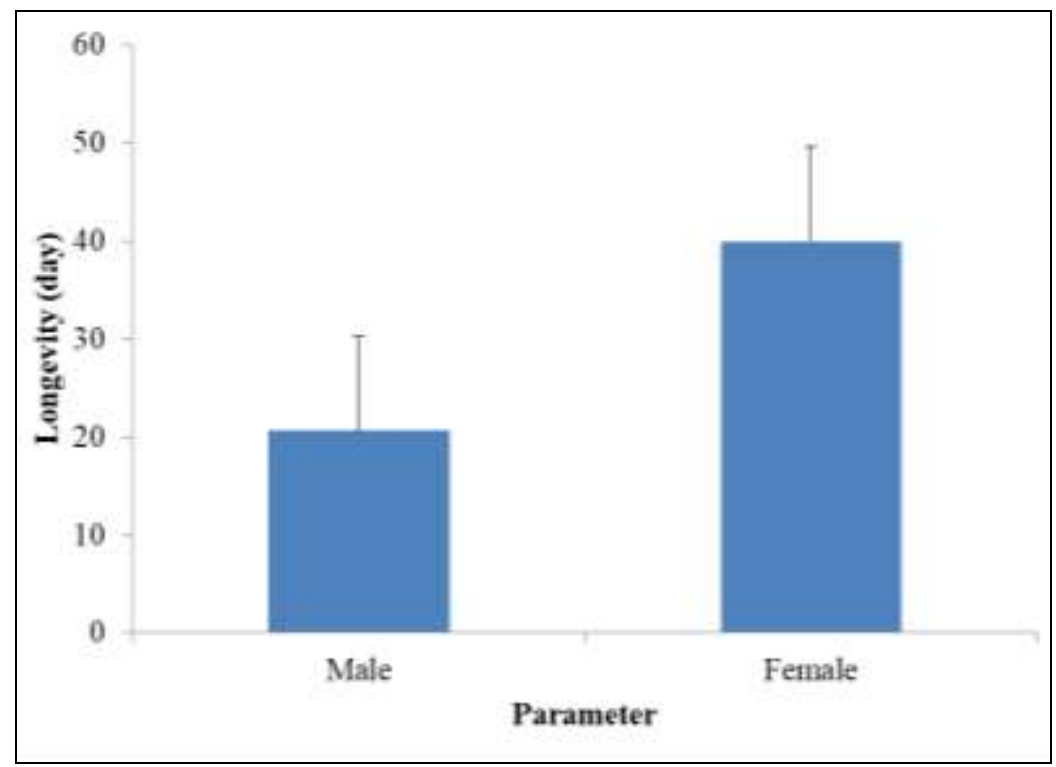

Fig 4: Longevity (mean \pm SE) of adult $P$. quatodecimpunctata

\section{Leaf consumption of hog plum leaf beetle}

\section{Weight basis}

The mean leaf consumption in terms of weight by a larva was $3.82 \mathrm{~g}$ during the entire larval period of 13.8 days. The 1st, 2nd, 3rd and 4th instars larvae consumed 0.074, 0.65, 0.96 and $2.13 \mathrm{~g}$ leaflet (Figure 5), respectively. It was observed that the final instars larva consumed highest quantity of food among the instars. The mean leaflet consumption by an adult was $8.96 \mathrm{~g}$. However, the insect consumed $12.78 \mathrm{~g}$ of leaflet during its life span. Hossain $e t$ al. (2004) ${ }^{[7]}$ reported that the mean leaf consumption of $P$. quatodecimpunctata was $11.79 \mathrm{~g}$. and those slightly differ but nearly close proximity to the present findings. 


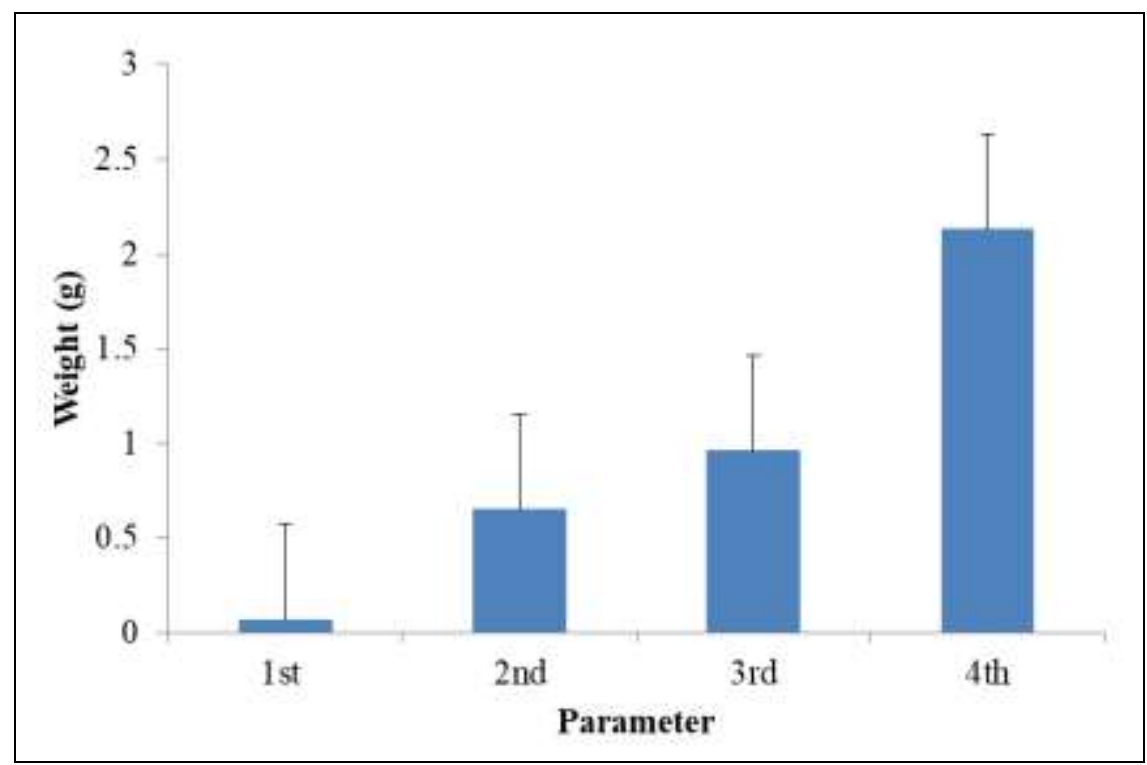

Fig 5: Leaf consumption pattern (weight basis) at different larval instars (mean \pm SE) of $P$. quatodecimpunctata

\section{Area basis}

The larvae consumed in an average of $0.66,5.93,7.6$, and $17.94 \mathrm{~cm}^{2}$ of leaves (Figure 6) during its life span. Hossian et al. (2004) ${ }^{[7]}$ stated that the mean leaf consumption of $P$. quatodecimpunctata was $95.41 \mathrm{~cm}^{2}$ which is slightly different to the present findings.

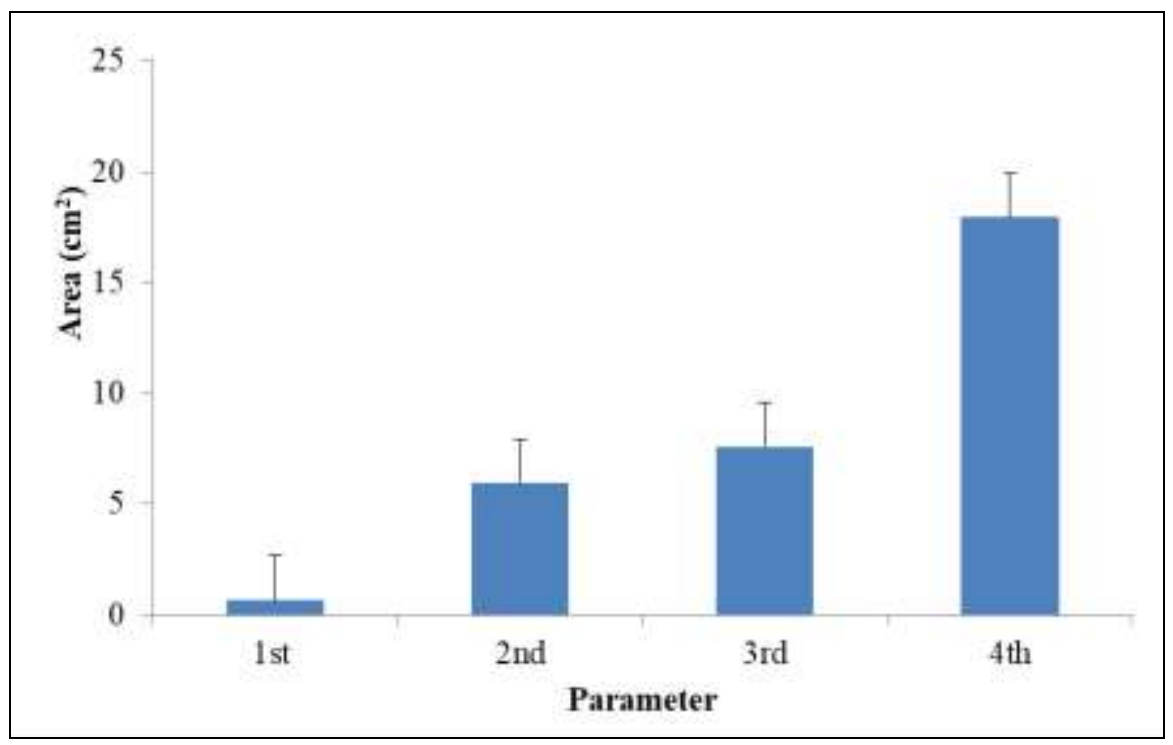

Fig 6: Leaf consumption (area basis) at different larval instars (mean $\pm \mathrm{SE}$ ) of $P$. quatodecimpunctata

\section{Acknowledgments}

The authors sincerely acknowledge the Institute of Research and Training (IRT), Hajee Mohammad Danesh science and Technology University, Dinajpur for its financial (17-18) supports for the research work.

\section{References}

1. Ahmed F, Alam MZ. Mango leaf consumption by Cricula trifenestrata Helder (Saturniidae: Lepidoptera) larvae under field condition. Bangladesh. Journal of Entomology 1993;3(1):9-17.

2. Amin MRMA, Ahad, Rono MA, Tithi DA. Life history traits of Cricula trifenestrata Helfer (Saturniidae: Lepidoptera) feeding on Magnifera indica. Journal of Agofor. Environ 2008;2(1):56-62.

3. Baksha MW. Biology, ecology and control of amra defoliator, Podntia quatodecimpunctata Linn.
(Chrysomelidae: Coleoptera) in Bangladesh. Bangladesh J. For. Sci. 1997;26(1):43-46.

4. Barlow E. Notes on insect pests from the Entomology. Section, Indian Museum. Indian Museum Notes. 1900;4:56-78.

5. Beeson CFC. The ecology and control of forest insects of India and neighboring countries. Government of India Press, Delhi 1941, 229.

6. Chowdhury SP, Ahad MA, Amin MR, Hasan MS. Biology of lady beetle Micraspis discolor (Fab.) (Coccinellidae: Coleoptera). Internatinal Journal of Sustain. Crop Production 2008;3(3):45-48

7. Hossain MA, Taj HFE, Ahad MA, Ara R. Biology and food consumption of hog plum leaf beetle, Podotia quatodecimpunctata L. Journal of Subtropic Agriculture Research and Development 2004;2:45-50. 
8. Husain M, Ahmad M. Notes on chrysomelid beetles (Coleoptera) of the BAU area, Mymensingh. Bangladesh Journal of Zoololgy 1977;5:71-75.

9. Karim SMA, Ahad, Amin MR, Iqbal TMT. Biolology of lemon butterfly Papilio demoleus L. (Papilionidae: Lepidoptera). Bangladesh Journal of Science and Technology 2008;5:28-34.

10. Lefroy HM. Indian Insect Life. Today and Tomorrow's Print Pub. New Delhi, India 1971, 360.

11. Mondal MA. Studies on the biology and control of fourteen spotted leaf beetle, $P$. quatodecimpunctata (Coleoptera: Chrysomelidae) on the hogplum. M.S. Thesis, Dept. Entomol. BAU, Mymensingh 1975.

12. Mondal MA, Amin MR. "Phaler Bagan". Ed. By Mrs. Afia Mondal, Club building (First floor), BAU campus, Mymensingh (in Bengali). 1990, 215.

13. Sardar MA, Mondal A. Bio-ecology and chemical control of $P$. quatodecimpunctata (Linn.) on hog plum. Indian Journal of Agricultural Science 1983;53(8):745748.

14. Singh P, Misra RM. Bionomics of the ambara defoliator Podondia 14-punctata Linn. (Coleoptera: Chrysomelidae). Indian Forester 1989;115(12):910915.

15. Singh RV. Fodder trees of India. Oxford and IBH Publishing Co. 1982, 663.

16. Stebbing EP. Indian forest insects of economic importance: Coleoptera. J. K. Jain Brothers, Bhopal 1914, 648. 